\title{
Molecular epidemiology, evolution and phylogeny of foot-and-mouth disease virus
}

\author{
Jamal, Syed Muhammad ; Belsham, Graham J
}

Published in:

Infection, Genetics and Evolution

Link to article, DOI:

10.1016/j.meegid.2018.01.020

Publication date:

2018

Document Version

Peer reviewed version

Link back to DTU Orbit

Citation (APA):

Jamal, S. M., \& Belsham, G. J. (2018). Molecular epidemiology, evolution and phylogeny of foot-and-mouth disease virus. Infection, Genetics and Evolution, 59, 84-98. https://doi.org/10.1016/j.meegid.2018.01.020

\section{General rights}

Copyright and moral rights for the publications made accessible in the public portal are retained by the authors and/or other copyright owners and it is a condition of accessing publications that users recognise and abide by the legal requirements associated with these rights.

- Users may download and print one copy of any publication from the public portal for the purpose of private study or research.

- You may not further distribute the material or use it for any profit-making activity or commercial gain

- You may freely distribute the URL identifying the publication in the public portal

If you believe that this document breaches copyright please contact us providing details, and we will remove access to the work immediately and investigate your claim. 
Molecular epidemiology, evolution and phylogeny of foot-and-mouth disease virus

\section{Syed M. Jamal ${ }^{1}$ \& Graham J. Belsham ${ }^{2} *$}

1: Department of Biotechnology, University of Malakand, Chakdara, Dir (L), Khyber Pakhtunkhwa, Pakistan

2: DTU National Veterinary Institute, Technical University of Denmark, Lindholm, Kalvehave 4771, Denmark

*Corresponding author: Graham J. Belsham, e-mail grbe@vet.dtu.dk

Short title: Molecular epidemiology of FMDV

Words: 5871 (excluding references and Figure legends)

Figures: 10

Tables: 0

Keywords: sequencing, lineage, serotype, picornavirus, RNA 


\begin{abstract}
Foot-and-mouth disease virus (FMDV) is responsible for one of the most economically important infectious diseases of livestock. The virus spreads very easily and continues to affect many countries (mainly in Africa and Asia). The risks associated with the introduction of FMDV result in major barriers to trade in animals and their products. Seven antigenically distinct forms of the virus are known, called serotypes, but serotype $\mathrm{C}$ has not been detected anywhere for many years and may now be extinct. The serotypes have been further divided into topotypes (except for serotype Asia-1 viruses, which comprise a single topotype), genotypes, lineages and sub-lineages, which are usually restricted to specific geographical regions. However, sometimes, trans-regional spread of some strains occurs. Due to the errorprone replication of the RNA genome, the virus continuously evolves and new strains frequently arise (e.g. with modified antigenicity). Using nucleotide sequencing technologies, this rapid evolution of the viral genome can be followed. This allows the tracing of virus transmission pathways within an outbreak of disease if (near) full-length genome sequences can be generated. Furthermore, the movement of distinct virus lineages, from one country to another can be analysed. Some important examples of the spread of new strains of FMD virus are described.
\end{abstract}




\section{Highlights}

- Seven different serotypes of FMDV exist

- The nucleotide sequence encoding the capsid protein VP1 is sufficient to identify the serotype and the lineage

- Phylogenetically related virus subtypes/strains within each serotype of FMDV are usually restricted to distinct geographical regions

- The nucleotide sequence of FMDV evolves very rapidly (upto about $1 \%$ of the genome per year)

- (Near) full-length genome sequencing of the virus allows virus transmission pathways to be established

- New strains of FMDV continue to arise, these can spread rapidly and can be threats to disease free areas 


\subsection{Introduction}

Foot-and-mouth disease (FMD) is an economically important disease of cloven-hoofed animals, affecting a variety of different species of domestic and wild livestock, including cattle, pigs, sheep, goats and buffalo. Although Europe and North America are usually free of the disease, it is still endemic in large parts of Asia and Africa (Jamal and Belsham, 2013). Sporadic cases of the disease occur in some South American countries. Outbreaks due to serotype O FMDV were reported in Colombia in June 2017 (OIE, 2017a) although no clinical disease had previously been detected anywhere in South America since 2013 when disease was reported in Venezuela. The causative agent of the disease, foot-and-mouth disease virus (FMDV), has a single stranded, positive sense, RNA genome (ca. 8,400 nucleotides (nt) in length) and belongs to the Aphthovirus genus within the family Picornaviridae. Within the virus particles, the genome is packaged in a protein shell that is composed of 60 copies of 4 different proteins, termed VP1, VP2, VP3 and VP4 (Figure 1). These individual virus proteins are produced by proteolytic processing of the polyprotein that is encoded by a single, large, open reading frame (ORF, ca. 7000 nt) within the viral RNA (Figure 1). The polyprotein of FMDV includes two separate proteases $\left(\mathrm{L}^{\mathrm{pro}}\right.$ and $\left.3 \mathrm{C}^{\mathrm{pro}}\right)$. The viral structural proteins are derived from the P1-2A capsid precursor (Figure 1). The non-structural proteins (NSPs) are mainly involved in the replication of the virus and modifying the host cell responses to infection (reviewed in Martinez-Salas and Belsham, 2017). The virus exists in seven antigenically distinct forms, called serotypes, i.e. O, A, C, Asia-1, Southern African Territories (SAT) 1, 2 and 3. The serotype is determined by the surface exposed capsid proteins VP1, VP2 and VP3 (note that the VP4 is located internally within the virus particle, see Acharya et al., 1989). There is no cross-protection between these serotypes so animals vaccinated or infected with one serotype remain susceptible to infection by the other serotypes (Rodriguez and Grubman, 2009). 
The serotypes $\mathrm{O}, \mathrm{A}$ and $\mathrm{C}$ have had a worldwide distribution, with serotype $\mathrm{O}$ being responsible for the majority of the outbreaks globally. In contrast, serotype Asia- 1 and the SAT viruses are normally restricted to Asia and sub-Saharan Africa, respectively (Rweyemamu et al., 2008). However, there has been an incursion of serotype Asia-1 viruses as far west as Greece in 2000 (Valarcher et al., 2008) and occasional incursions of SAT 1 and SAT 2 viruses from Africa into the Middle East (Rweyemamu et al., 2008; see below in section 3.1.8). The last outbreaks of FMD due to serotype C viruses were recorded in 2004 in Brazil and Kenya (Rweyemamu et al., 2008; Roeder and Knowles, 2009; Sangula et al., 2011) and this serotype is now apparently extinct. It is, however, worth mentioning that a SAT 3 serotype FMDV was identified from Uganda from a sample collected in 2013 after a period of more than 15 years without detection in that region. Indeed, the most recently reported isolation of SAT 3 FMDV, previous to this, was in South Africa in 2006. The recent Ugandan virus is of a different lineage than the South African viruses (Dhikusooka et al., 2015) and this latest isolate is most closely related to other, earlier, Ugandan strains of SAT 3 FMDV. The lack of detection of this virus in Uganda in the intervening years probably reflects the relatively infrequent sampling of the African buffalo populations in which these viruses are maintained.

Different subtypes exist within each serotype and new subtypes arise over time as the virus continually evolves (see below). Sometimes there is a lack of efficient cross-protection between different subtypes within a single serotype and thus characterization of subtypes becomes necessary for selection of appropriate vaccines to control an outbreak in countries where vaccination is employed. Different subtypes within each serotype are usually restricted to distinct geographical regions (Rweyemamu et al., 2008; Knowles et al., 2016a). Thus, FMDV subtypes within each serotype throughout the world have been sub-divided into seven regional pools (e.g., pool 2 comprises viruses from countries within the Indian sub-continent, 
except Pakistan, while pool 4 includes FMDVs from countries in North-eastern Africa).

These pools are based on genetic and antigenic analyses (see Di Nardo et al., 2011; Jamal and Belsham, 2013; Sumption et al., 2012). However, occasional spread of subtypes beyond their usual regions occurs.

\subsubsection{Error-prone replication of FMDV}

As with other picornaviruses, FMDV RNA replicates within the cytoplasm of infected cells (see Belsham and Bostock, 1988; Paul and Wimmer, 2015). This process requires the virus encoded RNA-dependent RNA polymerase ( $3 \mathrm{D}^{\mathrm{pol}}$, see Figure 1$)$. This enzyme catalyses the synthesis of a negative strand copy of the positive strand viral genome and then the nascent negative strand is used as the template for the production of new positive strand RNA molecules (reviewed in Paul and Wimmer, 2015). Far more positive strand RNAs are made than negative strands. The positive strand RNAs can be packaged by the virus capsid proteins to make new virus particles. All the FMDV RNA is linked at its 5'-terminus to one of the different versions of the 3B peptide (3B $\mathrm{B}_{1-3}$, also known as VPg, (King et al., 1980), see also Figure 1). The VPg acts as a protein primer for the synthesis of the viral RNA (Paul and Wimmer, 2015). The replication process is error prone, i.e. incorrect nt are incorporated into the RNA copies. Assessments of the error rate suggest that, on average, about 1 error is made for every 10,000 nt that are synthesized (Castro et al., 2005), i.e. nearly every genome has an error since almost $17,000 \mathrm{nt}$ have to copied to make one new positive strand (by copying the negative strand). There is no known mechanism of proof reading activity in picornaviruses and thus the viral RNA represents a pool of closely related sequences; this pool is known as a quasi-species (see Domingo et al., 2012). It seems that there is a balance between the need to maintain a functional RNA sequence and the need to be able to adapt to new conditions. Modifications to the fidelity (that either increase or decrease the error rate) of the $3 \mathrm{D}^{\text {pol }}$ from picornaviruses reduce the "fitness" of the virus (see Korboukh et al., 2014). As a result of this 
continuous generation of errors, the virus population is always evolving. The differences in sequence can modify the biology of the virus, (e.g. in its antigenicity or speed of replication) but can also be useful for identifying the sources of viruses that cause disease outbreaks.

A more dramatic form of genome evolution, involving RNA recombination, can also occur between picornavirus genomes. During the process of RNA replication, it is possible for the RNA polymerase $\left(3 \mathrm{D}^{\mathrm{pol}}\right)$ to switch from copying one positive strand template to another. This process can result in the formation of "chimeric" genomes, e.g. with the capsid coding sequences derived from one parental virus and some of the non-structural protein coding sequences derived from a different strain of virus (e.g. see Jamal et al., 2011b; Jackson et al., 2007). Clearly, it requires that an animal is co-infected with distinctly different strains of the virus to enable this process to be detected.

\subsection{Analysis of FMDV sequence evolution in the field}

There have been significant advances in the understanding of FMD epidemiology during the last three decades largely due to the application of molecular techniques including reversetranscription polymerase chain reaction (RT-PCR) and nucleotide (nt) sequencing (. These methods have become the preferred techniques for the genetic differentiation and characterization of FMDV strains. This methodology was first used for the study of the epidemiology of FMD by Beck and Strohmaier (1987), who investigated the origin of serotype $\mathrm{O}$ and A FMDV outbreaks in Europe over a 20 year period using the sequence (ca. 650nt) encoding the VP1 capsid protein (Figure 1). Soon afterwards, phylogenetic analysis of nucleotide coding sequences for the VP1 of FMDVs from serotypes $\mathrm{O}$, A and $\mathrm{C}$ was published (Dopazo et al., 1988). Together, these studies provided an early insight into the genetic relationships between different FMDVs and highlighted certain regions within the 
VP1 coding region that were diverse between strains while other regions were highly conserved. Since then, many studies have published nucleotide sequence analysis for all the seven serotypes of FMDV (e.g., Ayelet et al., 2009; Cottam et al., 2008a, b; Jamal et al., 2011a, b, c; Valarcher et al., 2009; Sangula et al., 2011; Valdazo-González et al., 2012a; Dhikusooka et al., 2015). Over time, as sequencing technologies have improved, it has become easier to generate such data and it has become increasingly common to analyze (near) complete (ca. 8400 nt) genome sequences (e.g. Carrillo et al. 2005, Cottam et al., 2008b; Jamal et al., 2011b; Valdazo-González et al., 2012a).

Different regions of the genome vary in their degree of conservation across the different serotypes of FMDV. Within the 5'-untranslated region (5'-UTR), the average nt identity between all serotypes is over $80 \%$ while for the entire polyprotein coding region (ca. $7000 \mathrm{nt}$ ) the lowest level of sequence identity between two isolates was 73\% (Carrillo et al., 2005). However, the VP1 coding region is substantially more variable and shows only about 50-70\% nt identity between all serotypes (Knowles and Samuel, 2003) and the encoded protein has the lowest proportion (24\%) of invariant amino acids among the different products derived from the polyprotein (Carrillo et al, 2005).

Knowledge of the nt sequence encoding VP1 is sufficient to classify a virus into its serotype and indeed the serotypes have been further classified into separate genotypes based on up to $15 \%$ difference in the VP1 coding sequences (Jamal et al., 2011c; Knowles and Samuel, 2003). On this basis, serotype O FMDVs, for example, from around the world have been classified into eight genetically and geographically distinct genotypes, which are referred to as topotypes (Knowles et al., 2016a). Similarly, a total of 26 regional genotypes have been identified within three continental topotypes (ASIA, AFRICA and EURO-SA) for serotype A FMDVs (Mohapatra et al., 2011), whereas, serotype Asia-1 FMDVs all belong to a single 
topotype, ASIA. The SAT 1, SAT 2 and SAT 3 viruses have been classified into 8 (I to VIII), 14 (I to XIV) and 5 (I to V) topotypes, respectively (Knowles et al., 2016a).

\subsection{Value of (near) full-length FMDV genome sequence}

Following introduction of FMDV into an area, which is normally disease-free, then the highly contagious nature of the virus means that the virus will spread rapidly among the animals within an infected premises and it can also spread easily to adjacent farms. During this process, as indicated above, the virus evolves due to its error prone mechanism of replication. In general, in the field, the virus consensus sequence changes at about $0.5-1 \%$ of its genome /yr (see Cottam et al., 2006). Thus, this means about 40-80nt changes accumulate per year or about 1-2 nt changes per week. Typically, during an outbreak, the virus infects a herd, spreads within it and is then transmitted to another herd; this process will take at least several days (maybe 1-2 weeks) and thus the virus population infecting different farms along a transmission pathway can be expected to be different. Analysis of the accumulation of nt changes within the virus in samples from each infected farm can therefore be used to identify a transmission pathway. This approach was used, retrospectively, on samples stored from the 2001 outbreak in the U.K. (Cottam et al., 2006). During the subsequent FMD outbreak in the U.K. in 2007, complete genome sequences were generated within 24-48 h of receipt and were then used to track virus transmission essentially in "real time". This information encouraged the search, using sero-surveillance, for an undisclosed, infected, premises that linked between the 2 separate phases of the outbreak (Cottam et al., 2008a,b). The viruses from the first and second phases of the outbreak differed by 9 nt whereas usually, as in the 2001 outbreak, farm to farm transmission was accompanied by only about 4 nt changes (Cottam et al., 2008a). The sero-surveillance indeed identified previously undetected infection in sheep that had been present on those premises for at least 2 weeks and appeared to represent the link between the 2 phases of the outbreak. 
When the latest outbreak of FMDV occurred in Europe, in Bulgaria in 2011, the identified cases within domestic livestock were sampled and sequence analysis of the viruses was performed. This outbreak also had two distinct phases but all the viruses collected had a single common ancestor. The viruses involved had VP1 coding sequences (ca. 640nt), that were almost identical to those from other viruses within the ANT-10 sub-lineage of O/MESA/PanAsia-2 that were known to be circulating, at that time, in Turkey and Israel (ValdazoGonzález et al., 2011). However, by generating near full-length genome sequences, (based on $8170 \mathrm{nt})$, then $44-60 \mathrm{nt}$ differences were identified between these sequences and the virus responsible for the first case in Bulgaria (Valdazo-González et al., 2012b). The precise origin of the virus introduced into Bulgaria was not apparent. However, it was possible to identify a transmission pathway within Bulgaria involving the two different phases of the outbreak. Apparent gaps in the transmission pathway again suggested that undisclosed outbreaks had occurred and this was subsequently confirmed by serological analysis. This outbreak of FMDV was unusual in that it was initially detected in wild boar and serological evidence for infection of these animals (and deer) in the near vicinity of infected domestic animals was obtained (Alexandrov et al., 2013). However, after the outbreaks in domestic animals were eliminated, then the disease was not maintained in the wildlife and no new infections of domestic animals occurred (see Dhollander et al., 2016).

These studies clearly show that useful information is generated by obtaining (near) full-length genome sequences. However, this process is fairly labour intensive, requiring the production and sequencing (in separate reactions) of multiple (5-20) RT-PCR products. Furthermore, this system only generates a consensus sequence; it does not give much information about the heterogeneity present within the virus populations. The advent of next generation sequencing (NGS), using a variety of different protocols for obtaining the sequence, can greatly facilitate 
the procedure for obtaining a consensus sequence and can also offer the capability of analyzing the diversity of the virus population at each position along the genome.

\subsection{Use of NGS for virus characterization}

A variety of different approaches can be used to generate the material for NGS. These approaches are, of course, applicable to many different viruses (e.g. influenza virus, hepatitis $\mathrm{C}$ virus, HIV etc.) and for a variety of different purposes. In some studies on FMDV (e.g. King et al., 2016; Kristensen et al., 2017; Wright et al., 2011), large amplicons (overlapping if more than 1) were generated by RT-PCR and then these products were used to generate consensus sequences. However, in addition, the fact that large numbers of sequence reads were generated (usually thousands of reads per nt) allowed the analysis of the heterogeneity within the viral sequences to be analyzed. This can permit, for example, the adaptation of the virus to be followed, either within cell culture (Kristensen et al., 2017) or during the course of infection within a single animal (Wright et al., 2011) or during the course of an outbreak (King et al., 2016). Variants, that initially only represent a few percent of the virus population, can rapidly increase during growth, in cell culture or in animals, and thus become dominant. This does illustrate the importance of analyzing samples without amplification in cell culture, if possible. New methods to improve the sensitivity of detection of such variants using NGS have been developed (e.g. circular sequencing, CirSeq, see review by Whitfield and Andino, 2016). No doubt, such analyses will increase the understanding of the virus quasi-species present within individual infected animals. Since there can be easily be over $10^{12}$ separate FMDV genomes circulating at any one time within the blood of a single, acutely infected bovine (Alexandersen et al., 2003), then even minor variants can still be present in large numbers. 
Recently, a protocol, using NGS, has been described for the generation of consensus level FMDV genome sequences without the need for the production of large amplicons by RTPCR (Logan et al., 2014). This system has been shown to work on all seven serotypes of the virus and with material from clinical samples (epithelium suspension) and from cell culture grown virus. It seems likely that this type of approach will become increasingly common. However, it should be noted that the short reads generated by NGS may impose some limitations on the ability to identify recombination between different FMDV strains, if samples could contain the parental strains as well as recombinant strains.

\subsection{Spread of important FMDV strains}

As described earlier, phylogenetically related virus subtypes/strains within each serotype of FMDV are usually restricted to distinct geographical regions. However, there are known exceptions and occasional spread of subtypes/strains beyond their usually defined region occurs. Well known examples include the spread of viruses belonging to the O-PanAsia lineage (a member of the Middle East South Asia (ME-SA) topotype) from South Asia to the whole of the Asian continent. This virus lineage caused outbreaks in previously disease-free countries like Japan and South Korea and also spread to South Africa and the European Union (Knowles et al., 2005). Some other examples of recent, important, spread of strains from outside their usual geographical region are described below.

\subsubsection{O/Ind-2001 lineage}

The O/Ind-2001 lineage was initially reported in India in 2001 as a group of FMDVs distinct from the then predominant O-PanAsia lineage (Hemadri et al., 2002). The virus lineage termed O/Ind-2001 was, in fact, present in the Middle East as early as 1997 since it was detected, by the World Reference Laboratory for FMD (WRL-FMD), in samples that originated from Kuwait, Bahrain and the United Arab Emirates collected in 1997 (Knowles et 
al., 2005). Sequencing of archived samples also revealed its existence in India as early as 1997 (Subramaniam et al., 2015). Continued circulation of this lineage was initially restricted to northern states of India, causing sporadic cases of FMD prior to 2008 and it was largely eclipsed by the PanAsia lineage during the period 2003-2007 but re-emerged in 2008 (Subramaniam et al., 2015). However, since 2009, the O/Ind-2001 lineage showed predominance throughout the country (Subramaniam et al., 2013) outcompeting the previously dominant PanAsia lineage (Das et al, 2012). Viruses belonging to the $\mathrm{O} / \mathrm{Ind}-2001$ lineage are native to India, Nepal, Bhutan and Bangladesh and these are classified as pool 2 viruses. Sporadic incursions of these viruses have also been recorded in Kuwait (1997), the United Arab Emirates (1997, 2001, 2008-2009), Bahrain (1997, 2001), Israel (2002), Saudi Arabia, Oman (2001), Palestinian Autonomous Territories (2002) and Iran (2009) but with no further known spread of this lineage outside its geographical region until 2013. Since its initial identification in 1997 (from Kuwait), this lineage has diverged over time into four distinct sub-lineages, designated as Ind-2001a, Ind-2001b, Ind-2001c and Ind-2001d. The Ind-2001a sub-lineage largely includes the FMDVs responsible for outbreaks during 20012002 in India (Subramaniam et al, 2013) and in the Middle East in 1997. The Ind-2001b sublineage emerged in the year 2001, whereas the Ind-2001c and Ind-2001d sub-lineages emerged in 2008 and 2009, respectively. All the outbreaks involving the O/Ind2001 lineage that have occurred since 2013, outside of the Indian sub-continent, were caused by the O/Ind2001d sub-lineage (Figure 2). During 2013-14, the O/Ind-2001d sub-lineage was detected in gazelles in the United Arab Emirates and in samples from dairy farms in Saudi Arabia (WRL-FMD, 2014). Viruses belonging to this sub-lineage also reached North Africa in 2013 and were then detected, for the first time, in Libya (in 2013), Tunisia (in 2014), Algeria (in 2014) and Morocco (in 2015). These countries had been free of FMD for the previous 15 years before these incursions and this lineage is now endemic in some of these countries 
(Bachanek-Bankowska et al., 2016; Knowles et al., 2016b; Valdazo-Gonzalez et al., 2014). Phylogenetic analysis of viruses responsible for the outbreaks in Saudi Arabia (during August to November, 2013) and Libya (during September to November, 2013) revealed that these viruses showed close similarity to the viruses from India and Bhutan that were collected during 2013. In addition, these studies provided evidence that the FMD outbreaks in Saudi Arabia and Libya arose through separate introductions of this virus strain into these countries (Knowles et al., 2016b). Furthermore, phylogenetic analysis of FMDVs circulating in Saudi Arabia during 2013-2016 showed two different "branches" of viruses belonging to the O/Ind2001d sub-lineage. Viruses responsible for outbreaks during 2013-2014 clustered together, whereas viruses collected during 2015-2016 formed a distinct cluster (WRL-FMD, 2016a). This branching pattern showed that two different incursions of FMDVs occurred into Saudi Arabia during 2013-2016. This strain was also detected in Jordan in February, 2017 (WRLFMD, 2017a). The O/Ind-2001d sub-lineage also spread to two islands in the Republic of Mauritius in the Indian Ocean in July 2016 (WRL-FMD, 2016b), a country which was previously free of FMD without vaccination. Surprisingly, there is no evidence for spread of the O/Ind-2001d sub-lineage into Egypt and Pakistan. Apart from this westward movement of the virus, the O/Ind-2001d strain also spread towards the east and was first detected in South East Asia (Laos, Myanmar and Vietnam) in 2015 (Arzt et al., 2017; Qiu et al., 2017; Vu et al., 2017). It spread to Thailand in September 2016 causing outbreaks in cattle, buffalo and pigs (WRL-FMD, 2016b; OIE, 2017b). The O/Ind-2001d viruses collected from Laos and Vietnam were closely related to each other and showed high similarity to viruses that had previously circulated in India in 2013. However, viruses from Myanmar and Thailand showed divergence from the viruses of the same sub-lineage recovered from Laos and Vietnam but were closely related to viruses circulating in Bangladesh in 2015 (OIE, 2017b; Qiu et al., 2017), indicating that two different incursions of this sub-lineage have occurred in 
South East Asia. The spread of this sub-lineage continues since it was also responsible for outbreaks in Mongolia in March 2015 (Nishi et al., 2017), in the eastern part of Russia in October 2016 and 2017 and in Western China (EuFMD, 2017). The O/Ind-2001d sub-lineage reached South Korea in February 2017 where it caused outbreaks in two separate regions (EuFMD, 2017; Ryoo et al., 2017). The VP1 coding sequences of FMDVs responsible for outbreaks in BoEun region showed closest identity (99.5\%) with the virus responsible for FMD outbreak in Russia in 2016 (Zabaikalskiv/3/RUS/2016), whereas, that responsible for the outbreak in JeongEup city showed closest identity (99.7\%) to an isolate from Bangladesh in 2015 (O/BAN/GO/ka-236) (Ryoo et al., 2017). The route of introduction of the O/Ind2001d sub-lineage into Russia and South Korea is difficult to ascertain, at present, due to the small extent of difference in sequences between these viruses and the non-availability of sequence data in public databases (at the time of writing). A map indicating the trans-regional spread of viruses belonging to the O/Ind-2001d sub-lineage is shown in Figure 3.

\subsubsection{O-PanAsia ${ }^{A N T-10}$ sub-lineage}

Serotype O FMDV belonging to a new sub-lineage within the O-PanAsia-II lineage was detected, for the first time, in a sample (O/TUR/12/2010) collected on June 19, 2010 from the East Anatolian region of Turkey. It was designated as the O-PanAsia-II ${ }^{\text {ANT-10 }}$ sub-lineage by the WRL-FMD, after the name of the region in Turkey from where it originated. Virus belonging to this sub-lineage was also subsequently detected in a sample (IRN/88/2009; accession No. KY091282) collected on December 21, 2009 from Esfahan, Iran. Retrospective analysis of samples (O/KHI/PAK/08/2009; accession No. JX170745) collected on May 28, 2009 from Karachi, Pakistan also detected this new sub-lineage, suggesting that the O-

PanAsia-II ${ }^{\text {ANT-10 }}$ sub-lineage may have originated from Pakistan (Brito et al., 2013). These 
viruses have become one of the most widely distributed sub-lineages observed in the whole West Eurasian Region. Outbreaks of FMD due to this sub-lineage were also reported in South Ossetia (a region of Georgia) in 2011 (WRL-FMD, 2011a). This sub-lineage reached Africa and was detected in a sample collected on December 22, 2010 from Tripoli, Libya (WRLFMD, 2011b). This sub-lineage has, however, not been detected in Egypt (see WRL-FMD website: www.wrlfmd.org for update).

As mentioned above, the O-PanAsia-II ${ }^{\text {ANT-10 }}$ sub-lineage was introduced into Europe and was detected in Bulgaria in a sample collected from wild boar on December 30, 2010 close to the border with Turkish Thrace, resulting in suspension of the FMD-free status of the country, which was previously disease-free since 1996. This outbreak was unusual in that it was first identified in wild boar and was only subsequently recognized within cattle, sheep, goats and swine in 12 outbreaks that lasted from the end of December 2010 until April, 2011. The epidemic was controlled by stamping out, quarantine and movement control. Bulgaria regained its FMD-free status in August 2012 (OIE, 2012). This was the most recent outbreak of FMD in Europe. A phylogenetic tree showing viruses belonging to the O-PanAsia-II ${ }^{\text {ANT-10 }}$ sub-lineage from different countries is shown in Figure 4 while Figure 5 shows the geographical spread of these viruses.

\subsubsection{O-EA-3 topotype}

Recently, outbreaks due to another serotype O FMDV were reported in the Palestinian Autonomous Territories and Israel in February, 2017. Sequencing revealed that these viruses belonged to the O/EA-3 topotype (WRL-FMD, 2017a), which is a component of the pool 4 viruses, normally restricted to Eastern Africa. These viruses are very closely related to the viruses currently circulating in Egypt (in 2017) and Ethiopia (in 2017) and are somewhat 
related to FMDVs circulating in Sudan in 2013 and in Egypt in 2015-16 (see WRL-FMD, $2017 b, c, d)$.

\subsubsection{A-Iran05 lineage}

The A-Iran05 lineage of FMDV was first identified in samples from Iran collected in 2003 (Knowles et al., 2009) and was then reported in samples from Afghanistan in 2004 (Klein et al., 2007; Schumann et al., 2008). This sub-lineage subsequently spread to Turkey and Saudi Arabia in 2005 and spread further in the Middle East, superseding other lineages like AIRN96 and A-IRN99 that were previously dominant in the region (Klein et al., 2006). This lineage was also detected in Pakistan and Jordan in 2006 and was responsible for extensive disease outbreaks in early 2006 within the Thrace region of Turkey. Viruses belonging to this lineage have evolved to form different sub-lineages including A-Iran05 ${ }^{\mathrm{AFG}-07}, \mathrm{~A}-\operatorname{Iran} 05^{\mathrm{BAR}-08}$,

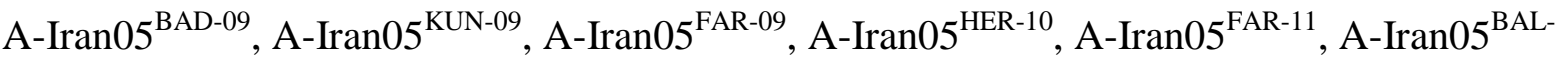
${ }^{11}$, etc. (Jamal et al., 2011c; Ullah et al., 2017) (see Figure 6). Viruses belonging to the AIran05 ${ }^{\text {BAR-08 }}$ were initially detected by WRL-FMD in samples from Bahrain collected from animals suspected of having FMD on November 24, 2008 (Knowles et al., 2009). However, it should be noted that Jamal et al. (2011c) reported the presence of this sub-lineage in an oral swab sample collected on July 23, 2008 from an apparently healthy animal in a live animal market in Kabul, Afghanistan. In early 2009, this sub-lineage reached Africa and was detected in Libya (WRL-FMD) and then during October 2010 in Egypt (WRL-FMD, 2012). The geographical spread of FMDVs belonging to the A-Iran05 ${ }^{\text {BAR-08 }}$ sub-lineage is shown in Figure 7. Surprisingly, no eastward spread of the A-Iran05 lineage has been reported. There is a poor antigenic match between the $\mathrm{A} / 22 / \mathrm{Iraq}$ vaccine and viruses belonging to the $\mathrm{A}$ Iran05 ${ }^{\text {BAR-08 }}$ sub-lineage (WRL-FMD 2009, 2010a, b, c). Mapping of the amino acid changes 
between the structural proteins of A22/Iraq and the A-Iran05 ${ }^{\text {BAR-08 }}$ viruses onto the A22/Iraq capsid structure revealed candidate amino acid substitutions exposed on the virus structure, which may explain this antigenic difference (Jamal et al., 2011c).

\subsubsection{A/Asia/G-VII}

Serotype A viruses belonging to the G-VII genotype were initially detected in the Indian State of Assam in 1989 from where they rapidly spread to other Indian states (Tosh et al., 2002). This genotype belongs to the pool 2 of FMD viruses and is thus native to the Indian subcontinent, excluding Pakistan. Viruses belonging to this genotype were also responsible for FMD outbreaks in Saudi Arabia in 1995-1996. This genotype also resulted in a large epidemic of FMD in Albania in 1996, due to importation of infected buffalo meat "on the bone” from India (Kitching, 1998; Valarcher et al., 2008). The disease spread further to Macedonia, from the neighbouring Albania, in the same year. Since then, viruses belonging to this genotype have not been reported outside their usual geographical region until 2015 when they were detected in Iran, Saudi Arabia, Turkey and Armenia (WRL-FMD, 2015). Outbreaks of disease due to serotype A FMDV had not been reported in Saudi Arabia since 2005, when outbreaks due to a virus belonging to the A-Iran05 lineage had occurred. During 2015, this G-VII genotype strain was detected for the first time in Armenia and Iran and again in Saudi Arabia in 2016 (WRL-FMD, 2015, 2016). A phylogenetic tree showing viruses belonging to the A/G-VII genotype is shown in Figure 8. In vitro and in vivo studies indicate that vaccine based on the A-Iran05 strain, which is currently in use in the West Eurasian region, is unlikely to provide efficient protection against this genotype. The A/G-VII genotype was detected in Israel in early 2017 (WRL-FMD, 2017b). New waves of infection due to this genotype have also occurred in Turkey during 2016 and the disease has spread to 
the margins of Anatolian Turkey, close to the FMD-free zone in the Thrace region (WRLFMD, 2016b), which poses a concern for spread of this genotype into Europe. A map showing the spread of A/G-VII viruses is shown in Figure 9.

\subsubsection{A/Africa/G-IV}

New FMD outbreaks have recently been detected in Algeria and Tunisia due to serotype A FMDV. These are the first cases of FMD due to serotype A in any Maghreb country in more than 30 years (King et al., 2017). These viruses have been characterized as belonging to the A/Africa/G-IV genotype and phylogenetic analysis showed a West African origin (WRLFMD, 2017a, b). Other recent field outbreaks due to this strain have been reported in Egypt (in 2015-16), Nigeria (in 2015), Cameroon (in 2013) and Ethiopia (in 2015) (WRL-FMD, 2017a, b, d).

\subsubsection{Group-VII (Sindh-08) of serotype Asia-1 virus}

A new genetic group within the serotype Asia-1 FMDVs emerged in recent years. Viruses belonging to this new genetic group within this serotype were first reported from Southern Pakistan in late 2008 and then in early 2009 and were named as Group-VII (Jamal et al., 2011b). The WRL-FMD designated this strain as Sindh-08 (Knowles et al., 2016a). This virus subsequently spread to other parts of the country and it was then detected in Iran in January 2011 and also in Afghanistan and Bahrain. This strain moved further eastwards and was detected in Turkey in June 2011. It was also reported in Tajikistan in the same year (WRLFMD, 2012) and is currently dominant throughout the West Eurasian regions and has completely replaced the Group-II and Group-VI viruses that were previously circulating in the region (Brito et al., 2017). FMD outbreaks due to this strain have not yet been reported outside its original geographical region. However, it has caused significant problems since the Asia-1/Shamir vaccine, which is frequently used to combat serotype Asia-1, does not provide 
sufficient protection against this virus (Knight-Jones et al., 2014). Indeed, viruses belonging to this genetic group are not efficiently neutralized by antisera raised against the Asia1/Shamir and Asia-1/Ind/8/79 vaccine strains (Jamal et al., 2011b). Fortunately, a homologous vaccine prepared using an isolate from this genetic group (Asia-1/TUR/11) that was responsible for an outbreak in Turkey in 2011, has been found to be effective for containing the spread of these Sindh-08 (Group-VII) viruses (Knight-Jones et al., 2014). A phylogenetic tree showing FMDVs belonging to the Sind-08 (Group-VII) is shown in Figure 10.

\subsubsection{SAT 2 topotypes VII and IV}

Widespread FMD outbreaks due to the SAT 2 serotype were reported in Egypt and Libya during February and March 2012 (Ahmed et al., 2012; FAO, 2012). These were the first outbreaks due to this serotype of FMDV in Egypt since 1950 and the first re-introduction of this serotype into Libya since 2003. The SAT 2 FMDVs responsible for outbreaks in Egypt in 2012 belonged to topotype VII of serotype SAT 2 FMDV. Viruses belonging to this topotype have previously been reported in Eritrea, Uganda, Cameroon, Nigeria and Sudan (Ahmed et al., 2012). The SAT 2 viruses responsible for the 2012 outbreaks in Egypt belonged to two different lineages within topotype VII i.e. Ghb-12 and Alx-12. The lineage SAT 2/VII/Ghb12 was responsible for outbreaks in Gharbia, Faiyum, Giza, Kafr el-Sheikh, Minya, Monufia, Qalyubia and Suiz Governorates, whereas, the SAT 2/VII/Alex-12 lineage was found in the Alexandria Governorate in Egypt (Ahmed et al., 2012). During April and May 2012, additional outbreaks due to SAT 2/VII/Ghb-12 lineage occurred in Egypt (WRL-FMD, 2012). The presence of two different lineages indicated two independent introductions of SAT 2 FMDVs in Egypt in 2012. The SAT 2 FMDVs responsible for outbreaks in Libya belonged to the Lib-12 lineage, which were not only distinct from the SAT 2 lineages in Egypt in 2012 but were also distinct from previous SAT 2 FMDVs responsible for outbreaks 
in 2003 in Libya (Ahmed et al., 2012). These finding suggest independent incursions of SAT 2 FMDVs into Libya and Egypt.

Outbreaks of disease due to SAT 2 FMDVs were reported in the Palestinian Autonomous Territories and in Bahrain in April, 2012. The SAT 2 virus from the Palestinian Autonomous Territories belonged to the SAT2/VII/Ghb-12 lineage and was most closely related to viruses from Egypt in 2012, showing 99.5\% nucleotide identity in the whole genome (ValdozoGonzalez et al., 2012a). The SAT 2 virus from Bahrain, however, belonged to the Ken-09 lineage within the topotype IV and was closely related to viruses occurring in Kenya in 2009. This was the first known detection of SAT 2 serotype in Bahrain (WRL-FMD, 2012). In April 2015, SAT 2/VII/Alex-12 lineage virus was detected in Oman which showed high similarity to the viruses circulating in Ethiopia in 2014-2015 (WRL-FMD, 2015).

\subsubsection{Concluding remarks}

FMDV remains an important threat to intensive animal production. The virus continuously evolves and sometimes new strains arise that display features which make them difficult to control, e.g. as with the serotype Asia-1 virus within Group-VII (Sindh-08) that is able to infect animals vaccinated with the commonly used vaccine strains (e.g. Asia-1/Shamir). However, it is interesting to note that some long established vaccine strains still have the ability to contain spread of the disease caused by "new" virus strains (see Mahapatra et al., 2017). Trans-pool movements of virus strain(s) can further complicate the epidemiological situation and disease control due to antigenic mismatch between the invader virus strain and the vaccine strain(s) already in use in the region. The emergence of $\mathrm{O} / \mathrm{Ind}$-2001d and A/Africa/G-IV viruses in the neighbourhood of Europe pose threats to these FMD-free countries. Such events highlight the ease with which FMD can cross international boundaries and emphasize the importance of continuous molecular epidemiological studies on the 
circulating viruses. The development of rapid, (near) full-length genome sequencing is a powerful tool for determining routes of virus transmission. Apparent gaps in such transmission chains have encouraged the search for unrecognized sites of infection and the discovery of such premises improves disease control. The knowledge of the virus genome sequences can also assist in the identification of specific changes in the virus capsid responsible for antigenic change. 


\section{References}

Acharya, R., Fry, E., Stuart, D., Fox, G., Rowlands, D., Brown, F., 1989. The threedimensional structure of foot-and-mouth disease virus at 2.9 A resolution. Nature 337, 709716.

Ahmed, H.A., Salem, S.A., Habashi, A.R., Arafa, A.A., Aggour, M.G., Salem, G.H., Gaber, A.S., Selem, O., Abdelkader, S.H., Knowles, N.J., Madi, M., Valdazo-Gonzalez, B., Wadsworth, J., Hutchings, G.H., Mioulet, V., Hammond, J.M., King, D.P., 2012. Emergence of foot-and-mouth disease virus SAT 2 in Egypt during 2012. Transbound. Emerg. Dis. 59, 476-481.

Alexandersen, S., Zhang, Z., Donaldson, A.I., Garland, A.J., 2003. The pathogenesis and diagnosis of foot-and-mouth disease. J. Comp. Pathol. 129, 1-36.

Alexandrov, T., Stefanov, D., Kamenov, P., Miteva, A., Khomenko, S., Sumption, K., Meyer-Gerbaulet, H., Depner, K., 2013. Surveillance of foot-and-mouth disease (FMD) in susceptible wildlife and domestic ungulates in Southeast of Bulgaria following a FMD case in wild boar. Vet. Microbiol. 166, 84-90.

Arzt, J., Brito, B., Pauszek, S.J., Hartwig, E.J., Smoliga, G.R., Vu, L.T., Vu, P.P., Stenfeldt, C., Rodriguez, L.L., Long, N.T., Dung, D.H., 2017. Genome Sequence of Foot-and-Mouth Disease Virus Serotype O Lineage Ind-2001d Collected in Vietnam in 2015. Genome Announc. 5, pii: e00223-17.

Ayelet, G., Mahapatra, M., Gelaye, E., Egziabher, B.G., Rufeal, T., Sahle, M., Ferris, N.P., Wadsworth, J., Hutchings, G.H., Knowles, N.J., 2009. Genetic characterization of foot-andmouth disease viruses, Ethiopia, 1981-2007. Emerg. Infect. Dis. 15, 1409-1417. 
Bachanek-Bankowska, K., Wadsworth, J., Gray, A., Abouchoaib, N., King, D.P., Knowles, N.J., 2016. Genome Sequence of Foot-and-Mouth Disease Virus Serotype O Isolated from Morocco in 2015. Genome Announc. 4, pii: e01746-15.

Beck, E., Strohmaier, K., 1987. Sub-typing of European foot-and-mouth disease virus strains by nucleotide sequence determination. J. Virol. 61, 1621-1629.

Belsham, G.J., Bostock, C.J., 1988. Studies on infectivity of foot-and-mouth disease virus RNA using microinjection. J. Gen. Virol. 69:265-274.

Brito, B.P., Mohapatra, J.K., Subramaniam, S., Pattnaik, B., 2017. Dynamics of widespread foot-and-mouth disease virus serotypes A, O and Asia-1 in southern Asia: A Bayesian phylogenetic perspective. Transbound. Emerg. Dis. DOI: 10.1111/tbed.12791 (in press).

Brito, B.P., Perez, A.M., Jamal, S.M., Belsham, G.J., Pauszek, S.J., Ahmed, Z., Rodriguez, L.L., 2013. Foot-and-mouth disease virus serotype O phylodynamics: genetic variability associated with epidemiological factors in Pakistan. Transbound. Emerg. Dis. 60:516-524.

Carrillo, C., Tulman, E.R., Delhon, G., Lu, Z., Carreno, A., Vagnozzi, A., Kutish, G.F., Rock, D.L., 2005. Comparative genomics of foot-and-mouth disease virus. J. Virol. 79, 6487-6504.

Castro, C., Arnold, J.J., Cameron, C.E. 2005. Incorporation fidelity of the viral RNAdependent RNA polymerase: a kinetic, thermodynamic and structural perspective. Virus Res. 2005. 107, 141-149.

Cottam, E.M., Haydon, D.T., Paton, D.J., Gloster, J., Wilesmith, J.W., Ferris, N.P., Hutchings, G.H., King, D.P., 2006. Molecular epidemiology of the foot-and-mouth disease virus outbreak in the United Kingdom in 2001. J. Virol. 80, 11274-11282. 
Cottam, E.M., Thébaud, G., Wadsworth, J., Gloster, J., Mansley, L., Paton, D.J., King, D.P., Haydon, D.T., 2008a. Integrating genetic and epidemiological data to determine transmission pathways of foot-and-mouth disease virus. Proc. R. Soc. B 275, 887-895.

Cottam, E.M., Wadsworth, J., Shaw, A.E., Rowlands, R.J., Goatley, L., Maan, S., Maan, N.S., Mertens, P.P., Ebert, K., Li, Y., Ryan, E.D., Juleff, N., Ferris, N.P., Wilesmith, J.W., Haydon, D.T., King, D.P., Paton, D.J., Knowles, N.J., 2008b. Transmission pathways of footand-mouth disease virus in the United Kingdom in 2007. PLoS Pathog. 4, e1000050.

Das, B., Sanyal, A., Subramaniam, S., Mohapatra, J.K., Pattnaik, B., 2012. Field outbreak strains of serotype $\mathrm{O}$ foot-and-mouth disease virus from India with a deletion in the immunodominant $\beta$ G- $\beta$ H loop of the VP1 protein. Arch. Virol. 157, 1967-1970.

Dhikusooka, M.T., Tjørnehøj, K., Ayebazibwe, C., Namatovu, A., Ruhweza, S., Siegismund, H.R., Wekesa, S.N., Normann, P., Belsham, G.J., 2015. Foot-and-mouth disease virus serotype SAT 3 in long-horned Ankole calf, Uganda. Emerg. Infect. Dis. 21, 111-114.

Dhollander, S., Belsham, G.J., Lange, M., Willgert, K., Alexandrov, T., Chondrokouki, E., Depner, K., Khomenko, S., Ozyoruk, F., Salman, M., Thulke, H.H., Botner, A., 2016. Assessing the potential spread and maintenance of foot-and-mouth disease virus infection in wild ungulates: general principles and application to a specific scenario in Thrace. Transbound. Emerg. Dis. 63, 165-174.

Di Nardo, A., Knowles, N.J., Paton, D.J., 2011. Combining livestock trade patterns with phylogenetics to help understand the spread of foot and mouth disease in sub-Saharan Africa, the Middle East and Southeast Asia. Rev. Sci. Tech. 30, 63-85.

Domingo, E., Sheldon, J., Perales, C. 2012. Viral quasispecies evolution. Microbiol. Mol. Biol. Rev. 76,159-216. 
Dopazo, J., Sobrino, F., Palma, E.L., Domingo, E., Moya, A., 1988. Gene encoding capsid protein VP1 of foot-and-mouth disease virus: a quasispecies model of molecular evolution. Proc. Natl. Acad. Sci. USA 85, 6811-6815.

EuFMD, 2017. 42nd General Session of the European Commission for the control of footand-mouth disease (EuFMD), April 20-21, 2017. Food and Agriculture Organization of the United Nations, Rome, Italy.

http://www.fao.org/ag/againfo/commissions/eufmd/commissions/eufmdhome/reports/general-sessions/en/

Hemadri, D., Tosh, C., Sanyal, A., Venkataramanan, R., 2002. Emergence of a new strain of type $\mathrm{O}$ foot-and-mouth disease virus: its phylogenetic and evolutionary relationship with the PanAsia pandemic strain. Virus Genes 25, 23-34.

FAO, 2012. Foot-and-mouth disease caused by serotype SAT2 in Egypt and Libya: A regional concern for animal health in North Africa and the Middle East. EMPRES watch Volume 25, March, 2012. Food and Agriculture Organization of the United Nations, Rome, Italy, page 1-7.

Jackson, A.L., O'Neill, H., Maree, F., Blignaut, B., Carrillo, C., Rodriguez, L., Haydon, DT., 2007. Mosaic structure of foot-and-mouth disease virus genomes. J Gen Virol. 88, 487-492.

Jamal, S.M., Belsham, G.J., 2013. Foot-and-mouth disease: past, present and future. Vet. Res. $44,116$.

Jamal, S.M., Ferrari, G., Ahmed, S., Normann, P., Belsham, G.J., 2011a. Genetic diversity of foot-and-mouth disease serotype O viruses from Pakistan and Afghanistan, 1997-2009. Infect. Genet. Evol. 11, 1229-1238. 
Jamal, S.M., Ferrari, G., Ahmed, S., Normann, P., Belsham, G.J., 2011b. Molecular characterization of serotype Asia-1 foot-and-mouth disease viruses in Pakistan and Afghanistan; emergence of a new genetic Group and evidence for a novel recombinant virus. Infect. Genet. Evol. 11, 2049-2062.

Jamal, S.M., Ferrari, G., Ahmed, S., Normann, P., Curry, S., Belsham, G.J., 2011c. Evolutionary analysis of serotype A foot-and-mouth disease viruses circulating in Pakistan and Afghanistan during 2002-2009. J. Gen. Virol. 92, 2849-2864.

King, A.M.Q., Sangar, D.V., Harris, T.J.R. and Brown F. 1980. Heterogeneity of the genome-linked protein of FMDV. J. Virol. 34, 627-634.

King, D., Mioulet, V., Ludi, A., Knowles, N., 2017. Update on the current global situation for FMD: Work of the OIE/FAO Network to detect new outbreaks and monitor threats. Global foot-and-mouth Research Alliance Scientific Meeting 2017. Incheon, South Korea, October 25-27, 2017. Retrieved from https://www.ars.usda.gov/gfra/GFRA Scientific Meeting 2017/GFRA 2017 Scientific Meeting Abstract Book.pdf (accessed on January 1, 2018).

King, D.J., Freimanis, G.L., Orton, R.J., Waters, R.A., Haydon, D.T., King, D.P., 2016. Investigating intra-host and intra-herd sequence diversity of foot-and-mouth disease virus. Infect. Genet. Evol. 44, 286-292.

Kitching, R., 1998. A recent history of foot-and-mouth disease. J. Comp. Path. 118, 89-108.

Klein, J., Parlak, U., Ozyoruk, F., Christensen, L.S., 2006. The molecular epidemiology of foot-and-mouth disease virus serotypes A and O from 1998 to 2004 in Turkey. BMC Vet. Res. 2, 35 . 
Klein, J., Hussain, M., Ahmad, M., Normann, P., Afzal, M., Alexandersen, S., 2007. Genetic characterization of the recent foot-and-mouth disease virus subtype A/IRN/2005. Virol. J. 4, 122.

Knight-Jones, T., Bulut, A., Gubbins, S., Stärk, K., Pfeiffer, D., Sumption, K., Paton, D., 2014. Retrospective evaluation of foot-and-mouth disease vaccine effectiveness in Turkey. Vaccine $32,1848-1855$.

Knowles, N.J., Samuel, A.R., 2003. Molecular epidemiology of foot-and-mouth disease virus. Virus Res. 91, 65-80.

Knowles, N.J., Samuel, A.R., Davies, P.R., Midgley, R.J., Valarcher, J.-F., 2005. Pandemic strain of foot-and-mouth disease virus serotype O. Emerg. Infect. Dis. 11, 1887-1893.

Knowles, N.J., Wadsworth, J., Bachanek-Bankowska, K., King, D.P., 2016a. VP1 sequencing protocol for foot and mouth disease virus molecular epidemiology. Rev. Sci. Tech. 35, 741755.

Knowles, N.J., Bachanek-Bankowska, K., Wadsworth, J., Mioulet, V., Valdazo-Gonzalez, B., Eldaghayes, I.M., Dayhum, A.S., Kammon, A.M., Sharif, M.A., Waight, S., Shamia, A.M., Tenzin, S., Wernery, U., Grazioli, S., Brocchi, E., Subramaniam, S., Pattnaik, B., King, D.P., 2016b. Outbreaks of foot-and-mouth disease in Libya and Saudi Arabia during 2013 due to an exotic O/ME-SA/Ind-2001 lineage virus. Transbound. Emerg. Dis. 63, e431-435.

Knowles, N.J., Nazem Shirazi, M.H., Wadsworth, J., Swabey, K.G., Stirling, J.M., Statham, R.J., Li, Y., Hutchings, G.H., Ferris, N.P., Parlak, U., Ozyörük, F., Sumption, K.J., King, D.P., Paton, D.J., 2009. Recent spread of a new strain (A-Iran-05) of foot-and-mouth disease virus type A in the Middle East. Transbound. Emerg. Dis. 56, 157-169. 
Korboukh, V.K., Lee, C.A., Acevedo, A., Vignuzzi, M., Xiao, Y., Arnold, J.J., Hemperly, S., Graci, J.D., August, A., Andino, R., Cameron, C.E. 2014. RNA virus population diversity, an optimum for maximal fitness and virulence. J. Biol. Chem. 289, 29531-29544.

Kristensen, T., Normann, P., Gullberg, M., Fahnoe, U., Polacek, C., Rasmussen, T.B., Belsham, G.J., 2017. Determinants of the VP1/2A junction cleavage by the 3C protease in foot-and-mouth disease virus-infected cells. J. Gen. Virol. 98, 385-395.

Logan, G., Freimanis, G.L., King, D.J., Valdazo-Gonzalez, B., Bachanek-Bankowska, K., Sanderson, N.D., Knowles, N.J., King, D.P., Cottam, E.M., 2014. A universal protocol to generate consensus level genome sequences for foot-and-mouth disease virus and other positive-sense polyadenylated RNA viruses using the Illumina MiSeq. BMC Genomics 15, 828.

Mahapatra, M., Upadhyaya, S., Aviso, S., Babu, A., Hutchings, G., Parida, S., 2017.

Selection of vaccine strains for serotype O foot-and-mouth disease viruses (2007-2012) circulating in Southeast Asia, East Asia and Far East. Vaccine. 35, 7147-7153.

Martinez-Salas, E., Belsham, G.J., 2017. Genome organization, translation and replication of foot-and-mouth disease virus RNA. Chapter 2., in: Sobrino, F., Domingo, E. (Eds.), Footand-mouth Disease: Current Research and Emerging Trends. Caister Academic Press, Norfolk, UK. pp13-42.

Mohapatra, J.K., Subramaniam, S., Pandey, L.K., Pawar, S.S., De, A., Das, B., Sanyal, A., Pattnaik, B., 2011. Phylogenetic structure of serotype A foot-and-mouth disease virus: Global diversity and the Indian perspective. J. Gen. Virol. 92, 873-879.

Nishi, T., Ulziibat, G., Khanui, B., Myagmarsuren, O., Morioka, K., Yamakawa, M., 
Fukai, K., 2017. Genome sequence of foot-and-mouth disease virus of serotype O lineage Ind-2001d isolated from cattle in Mongolia in 2015. Genome Announc. 5:e01244-17.

OIE, 2012. Report of the meeting of the OIE Scientific Commission for animal diseases. Paris, 27-31 August, 2012. Report No. 81 SG/12/CS3 A. Office International des Epizooties, Paris, France.

OIE, 2017a. Foot-and-mouth disease, Colombia. Retrieved from http://www.oie.int/wahis_2/public/wahid.php/Reviewreport/Review?reportid=24353 (accessed on December 30, 2017)

OIE, 2017b. FMD situation in SEACFMD countries 2015-2016. $23^{\text {rd }}$ SEACFMD SubCommission Meeting. 9-10 March, 2017, Siem Reap, Cambodia. Retrieved from http://www.oie.int/wahis_2/public/wahid.php/Reviewreport/Review?reportid=24353 (accessed on December 30, 2017).

Paul, A.V., Wimmer, E. 2015. Initiation of protein-primed picornavirus RNA synthesis. Virus Res. 206, 12-26.

Qiu, Y., Abila, R., Rodtian, P., King, D.P., Knowles, N.J., Ngo, L.T., Le, V.T., Khounsy, S., Bounma, P., Lwin, S., Verin, B.C., Widders, P., 2017. Emergence of an exotic strain of serotype O foot-and-mouth disease virus O/ME-SA/Ind-2001d in South-East Asia in 2015. Transbound. Emerg. Dis. e-pub Aug 30 2017. doi: 10.1111/tbed.12687

Rodriguez, L.L., Grubman, M.J., 2009. Foot and mouth disease virus vaccines. Vaccine. 27, Suppl 4:D90-94. doi: 10.1016/j.vaccine.2009.08.039.

Roeder, P.L., Knowles, N.J., 2009. The global control of FMD - Tools, ideas and ideals. Foot-and-mouth disease virus type $\mathrm{C}$ situation: The first target for eradication. Erice, Italy: 
FAO, Rome. Retrieved from

http://www.fao.org/ag/againfo/commissions/docs/research_group/erice/ppt_07.pdf

Rweyemamu, M., Roeder, P., Mackay, D., Sumption, K., Brownlie, J., Leforban, Y., Valarcher, J-F., Knowles, N.J., Saraiva, V., 2008. Epidemiological patterns of foot-andmouth disease worldwide. Transbound. Emerg. Dis. 55, 57-72.

Ryoo, S., Nah, J., Lee, H.J., Park, S.H., Sagong, M., Kim, T., Lee, J-W., Lee, S., Jung, S., Wee, S-H., Ku, B., 2017. Genetic characterization of foot-and-mouth disease virus serotype O in Republic of Korea, 2017. Global foot-and-mouth Research Alliance Scientific Meeting 2017. Incheon, South Korea, October 25-27, 2017. Retrieved from https://www.ars.usda.gov/gfra/GFRA Scientific Meeting 2017/GFRA 2017 Scientific Meeting Abstract Book.pdf (accessed on January 1, 2018).

Sangula, A.K., Siegismund, H.R., Belsham, G.J., Balinda, S.N., Masembe, C., Muwanika, V.B., 2011. Low diversity of foot-and-mouth disease serotype C virus in Kenya: evidence for probable vaccine strain re-introductions in the field. Epidemiol. Infect. 139, 189-196.

Schumann, K.R., Knowles, N.J., Davies, P.R., Midgley, R.J., Valarcher, J.F., Raoufi, A.Q., McKenna, T.S., Hurtle, W., Burans, J.P., Martin, B.M., Rodriguez, L.L., Beckham, T.R., 2008. Genetic characterization and molecular epidemiology of foot-and-mouth disease viruses isolated from Afghanistan in 2003-2005. Virus Genes 36, 401-413.

Subramaniam, S., Sanyal, A., Mohapatra, J.K., Sharma, G.K., Biswal, J.K., Ranjan, R., Rout, M., Das, B., Bisht, P., Mathapati, B.S., Dash, B.B., Pattnaik, B., 2013. Emergence of a novel lineage genetically divergent from the predominant Ind2001 lineage of serotype O foot-andmouth disease virus in India. Infect. Genet. Evol. 18, 1-7. 
Subramaniam, S., Mohapatra, J.K., Sharma, G.K., Biswal, J.K., Ranjan, R., Rout, M., Das, B., Dash, B.B., Sanyal, A., Pattnaik, B., 2015. Evolutionary dynamics of foot-and-mouth disease virus O/ME-SA/Ind2001 lineage. Vet. Microbiol. 178, 181-189.

Sumption, K., Domenech, J., Ferrari, G., 2012. Progressive control of FMD on a global scale. Vet. Rec. 637-639.

Tosh, C., Sanyal, A., Hemadri, D., Venkataramanan, R., 2002. Phylogenetic analysis of serotype A foot-and-mouth disease virus isolated in India between 1977 and 2000. Arch. Virol. 147, 493-513.

Ullah, A., Jamal, S.M., Romey, A., Gorna, K., Kakar, M.A., Abbas, F., Ahmad, J., Zientara, S., Bakkali Kassimi, L., 2017. Genetic characterization of serotypes A and Asia-1 foot-andmouth disease viruses in Balochistan, Pakistan, in 2011. Transbound. Emerg. Dis. 64, 15691578.

Valarcher, J.F., Leforban, Y., Rweyemamu, M., Roeder, P.L., Gerbier, G., Mackay, D.K., Sumption, K.J., Paton, D.J., Knowles, N.J., 2008. Incursions of foot-and-mouth disease virus into Europe between 1985 and 2006. Transbound. Emerg. Dis. 55, 14-34.

Valarcher, J.-F., Knowles, N.J., Zakharov, V., Scherbakov, A., Zhang, Z., Shang, Y.-J., Liu, Z.-X., Liu, X.-T., Sanyal, A., Hemadri, D., Tosh, C., Rasool, T.J., Pattnaik, B., Schumann, K.R., Beckham, T.R., Linchongsubongkoch, W., Ferris, N.P., Roeder, P.L., Paton, D.J., 2009. Multiple origins of foot-and-mouth disease virus serotype Asia 1 outbreaks, 2003-2007. Emerg. Infect. Dis. 15, 1046-1051.

Valdazo-González, B., Knowles, N.J., Wadsworth, J., King, D.P., Hammond, J.M., Ozyörük, F., Firat-Saraç, M., Parlak, U., Polyhronova, L., Georgiev, G.K., 2011. Foot-and-mouth disease in Bulgaria. Vet. Rec. 168, 247. 
Valdazo-González, B., Knowles, N., Hammond, J., King, D., 2012a. Genome Sequences of SAT 2 Foot-and-Mouth Disease Viruses from Egypt and Palestinian Autonomous Territories (Gaza Strip). J. Virol. 86, 8901-8902.

Valdazo-González, B., Polihronova, L., Alexandrov, T., Normann, P., Knowles, N.J., Hammond, J.M, Georgiev, G.K., Özyörük, F., Sumption, K.J., Belsham, G.J., King, D.P, 2012b. Reconstruction of the transmission history of RNA virus outbreaks using full genome sequences: foot-and-mouth disease virus in Bulgaria in 2011 PLoS ONE 7, e49650.

Valdazo-Gonzalez, B., Knowles, N.J., King, D.P., 2014. Genome Sequences of Foot-andMouth Disease Virus O/ME-SA/Ind-2001 Lineage from Outbreaks in Libya, Saudi Arabia, and Bhutan during 2013. Genome Announc. 2, pii: e00242-14.

Vu, L.T., Long, N.T., Brito, B., Stenfeldt, C., Phuong, N.T., Hoang, B.H., Pauszek, S.J., Hartwig, E.J., Smoliga, G.R., Vu, P.P., Quang, L.T.V., Hung, V.V., Tho, N.D., Dong, P.V., Minh, P.Q., Bertram, M., Fish, I.H., Rodriguez, L.L., Dung, D.H., Arzt, J., 2017. First detection of foot-and-mouth disease virus O/Ind-2001d in Vietnam. PLoS ONE 12, $\mathrm{e} 0177361$.

Whitfield, Z.J., Andino, R., 2016. Characterization of Viral Populations by Using Circular Sequencing. J. Virol. 90, 8950-8953.

Wright, C.F., Morelli, M.J., Thebaud, G., Knowles, N.J., Herzyk, P., Paton, D.J., Haydon, D.T., King, D.P., 2011. Beyond the consensus: dissecting within-host viral population diversity of foot-and-mouth disease virus by using next-generation genome sequencing. J. Virol. 85, 2266-2275. 
WRL-FMD, 2009. Annual OIE/FAO FMD Reference Laboratory Network Report, January December 2009. Institute for Animal Health, Pirbright Laboratory, United Kingdom. Pp 1-67. (available at www.wrlfmd.org).

WRL-FMD, 2010a. WRL-FMD Quarterly Report January-March 2010. Reference Laboratory Contract Report No. 4/27/2010. Institute for Animal Health, Pirbright Laboratory, United Kingdom. Pp 1-30 (available at www.wrlfmd.org).

WRL-FMD, 2010b. WRL-FMD Quarterly Report April-June 2010. Reference Laboratory Contract Report No. 7/15/2010. Institute for Animal Health, Pirbright Laboratory, United Kingdom. Pp 1-32 (available at www.wrlfmd.org).

WRL-FMD, 2010c. WRLFMD Quarterly Report July-September 2010. Reference Laboratory Contract Report No. 10/25/2010. Institute for Animal Health, Pirbright Laboratory, United Kingdom. Pp. 1-26 (available at www.wrlfmd.org).

WRL-FMD, 2011a. OIE/FAO FMD Reference Laboratory Network Annual Report 2011. Institute for Animal Health, Pirbright Laboratory, United Kingdom (available at www.wrlfmd.org).

WRL-FMD, 2011b. Genotyping Report FMDV type O. Batch No. WRLFMD/2011/000001. FAO World Reference Laboratory for foot-and-mouth disease (WRLFMD), Institute for Animal Health, Pirbright Laboratory, United Kingdom (available at www.wrlfmd.org).

WRL-FMD, 2012. OIE/FAO FMD Reference Laboratory Network Annual Report 2012. Institute for Animal Health, Pirbright Laboratory, United Kingdom (available at www.wrlfmd.org). 
WRL-FMD, 2014. OIE/FAO FMD Reference Laboratory Network Annual Report 2014. Institute for Animal Health, Pirbright Laboratory, United Kingdom (available at www.wrlfmd.org).

WRL-FMD, 2015. OIE/FAO FMD Reference Laboratory Network Annual Report 2015. Institute for Animal Health, Pirbright Laboratory, United Kingdom (available at www.wrlfmd.org).

WRL-FMD, 2016a. Genotyping Report FMDV type O. Batch No. WRLFMD/2016/00011. FAO World Reference Laboratory for foot-and-mouth disease (WRLFMD), Institute for Animal Health, Pirbright Laboratory, United Kingdom (available at www.wrlfmd.org).

WRL-FMD, 2016b. OIE/FAO FMD Reference Laboratory Network Annual Report 2016. Institute for Animal Health, Pirbright Laboratory, United Kingdom (available at www.wrlfmd.org).

WRL-FMD, 2017a. OIE/FAO FMD Reference Laboratory Network Quarterly Report January to March, 2017. Institute for Animal Health, Pirbright Laboratory, United Kingdom (available at www.wrlfmd.org).

WRL-FMD, 2017b. OIE/FAO FMD Reference Laboratory Network Quarterly Report April to June, 2017. Institute for Animal Health, Pirbright Laboratory, United Kingdom (available at www.wrlfmd.org).

WRL-FMD, 2017c. Genotyping Report FMDV type O. Batch No. WRLFMD/2017/00007. FAO World Reference Laboratory for foot-and-mouth disease (WRLFMD), Institute for Animal Health, Pirbright Laboratory, United Kingdom (available at www.wrlfmd.org). 
WRL-FMD, 2017d. OIE/FAO FMD Reference Laboratory Network Quarterly Report July to September, 2017. Institute for Animal Health, Pirbright Laboratory, United Kingdom (available at www.wrlfmd.org).

\section{Figure legends}

Figure 1. Genome organization of FMDV. The RNA genome encodes a polyprotein that is processed, largely by virus-encoded proteases into 15 mature products. The virus capsid comprises 60 copies of VP1, VP2, VP3 and VP4 while the non-structural proteins are mainly involved in virus replication (e.g. $3 \mathrm{D}^{\mathrm{pol}}$ ).

Figure 2. Neighbour-Joining phylogenetic tree showing different sub-lineages within the FMDV O/ME-SA/Ind-2001 lineage. The tree was constructed using MEGA 7 using selected nucleotide sequences $(\mathrm{nt}=639)$ encoding the capsid protein VP1 that are available in public databases. The sequences were included to show different sub-lineages within the O/Ind-2001 lineage plus some reference sequences (e.g., O/UKG/35/2001 and O1/Manisa/Turkey/69).

\section{Figure 3. Trans-regional spread of FMD viruses belonging to the O/Ind-2001d sub-} lineage. The O/Ind-2001d sub-lineage is native to countries marked in red. Countries where outbreak(s) due to the O/Ind-2001d sub-lineage have been recorded are shown in blue except for Russia where the region of the outbreak is shown in yellow. Arrows indicate the transregional spread and the year indicates the first recorded introduction into the respective countries. Dotted arrows indicate unknown routes of introduction.

Figure 4. Neighbouring-Joining phylogenetic tree including FMDVs belonging to the $\mathrm{O}$ PanAsia-II ${ }^{\text {ANT-10 }}$ sub-lineage. The tree was constructed using MEGA 7 using selected 
nucleotide sequences $(\mathrm{nt}=639)$ encoding the capsid protein VP1 that are available in public databases. The sequences were included to show viruses belonging to the O-PanAsia-II ${ }^{\text {ANT-10 }}$ sub-lineages with some representative viruses belonging to the O-PanAsia lineage and a group of viruses belonging to the $\mathrm{O} /$ Ind-2001 lineage.

\section{Figure 5. Trans-regional spread of viruses belonging to the O-PanAsia-II ${ }^{\mathrm{ANT}-10}$ sub-} lineage. The O-PanAsia-II ${ }^{\text {ANT-10 }}$ sub-lineage is native to countries marked in red. Countries where trans-regional outrbreak(s) due to the O-PanAsia-II ${ }^{\text {ANT-10 }}$ sub-lineage have been recorded are shown in blue. The year of first recorded introduction of the virus is shown on the countries.

Figure 6. Neighbour-Joining phylogenetic tree showing the different sub-lineages within the A-Iran05 lineage. The tree was constructed using MEGA 7 using selected nucleotide sequences $(n t=639)$ encoding the capsid protein VP1 that are available in public databases. The sequences included are from different sub-lineages within the A-Iran05 lineage plus some representative sequences belonging to the A-IRN99, A-IRN-96 and A-IRN-87 lineages and a reference sequence (A22/Iraq/64).

Figure 7. Trans-regional spread of viruses belonging to the A-Iran05 ${ }^{\mathrm{BAR}-08}$ sub-lineage. The A-Iran05 ${ }^{\mathrm{BAR}-08}$ sub-lineage is native to countries marked in red. Countries where transregional outrbreak(s) due to the A-Iran $05^{\mathrm{BAR}-08}$ sub-lineage have been recorded are shown in blue. The year of first recorded introduction of the virus is shown on the countries.

\section{Figure 8. Neighbour-Joining phylogenetic tree showing FMDVs belonging to the A/G-}

VII genotype. The tree was constructed using MEGA 7 using selected nucleotide sequences (nt=639) encoding the capsid protein VP1 that are available in public databases. The tree also shows viruses belonging to the A-Iran05, A-IRN99 and A-IRN87 lineages and a reference sequence (A22/Iraq/64). 
Figure 9. Trans-regional spread of viruses belonging to the A/Asia/G-VII genotype. The A/Asia/G-VII genotype is native to countries marked in red. Countries where outbreak(s) due to the A/Asia/G-VII genotype have been recorded are shown in blue. Arrows indicate the trans-regional spread and the year of first recorded introduction of the virus is indicated.

\section{Figure 10. Phylogenetic tree showing FMDVs belonging to the Sindh08 (Group-VII)}

within the Asia-1 serotype. The tree was constructed using MEGA 7 using selected nucleotide sequences $(\mathrm{nt}=633)$ encoding the capsid protein VP1 that are available in public databases. Other strains/groups of serotype Asia-1 FMDVs circulating in West Eurasian region also also shown. 


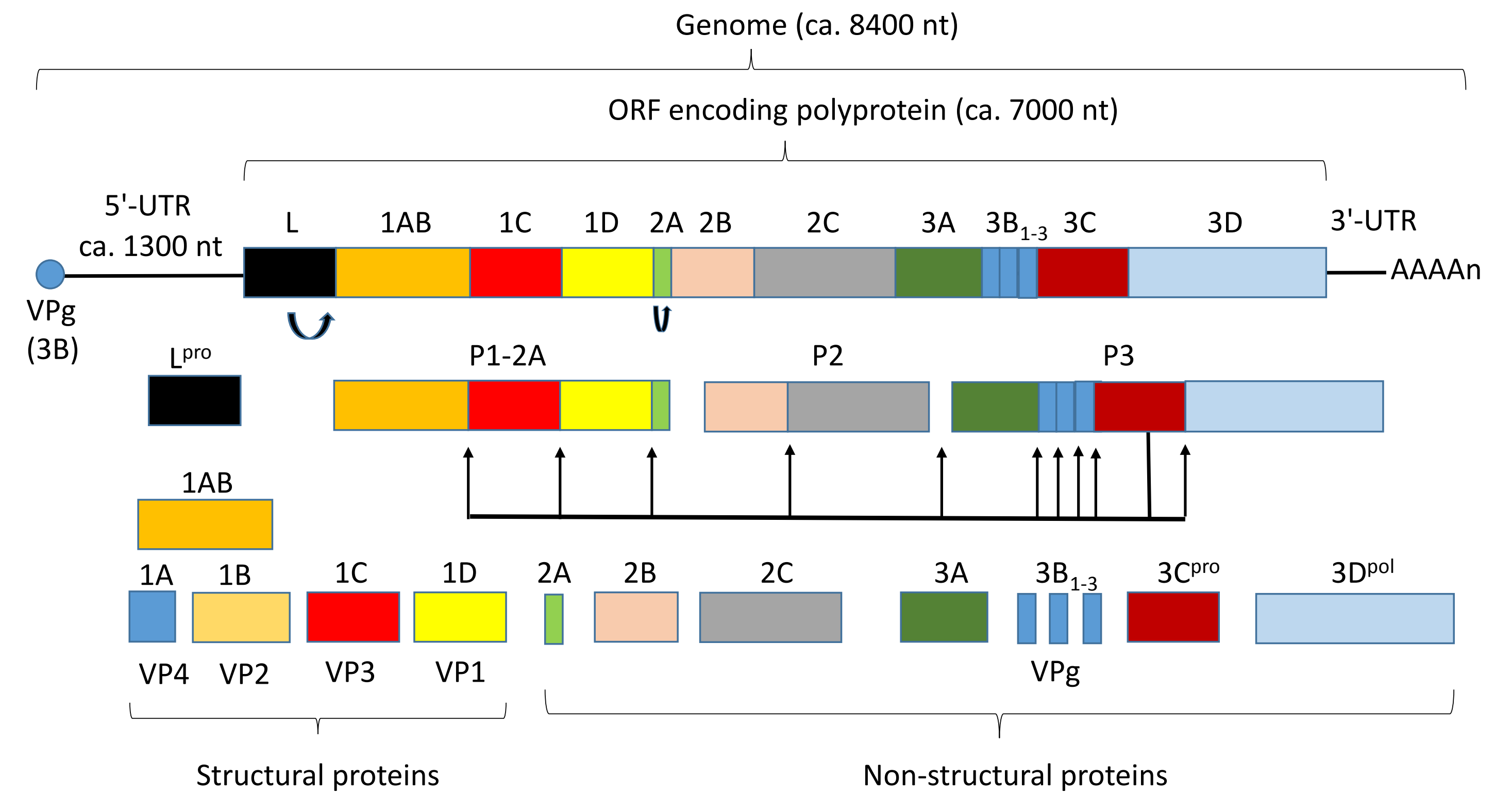


— O/NEP/6/2014 (KM921865)

- O/BAN JA Ma-180 2013 (KJ175183)

O/IND205/2013 (KM264362)

O/IND250(541)/2013 (KJ825809)

- O/NEP/3/2013 (KM921853)

- O/NEP/1/2014 (KM921861)

38 O/NEP/2/2014 (KM921862)

- O/IND 32/14 (KP822942)

- O/IND219/2013 (KM264363)

C O/NEP/11/2013 (KM921855)

- O/NEP/12/2013 (KM921856)

- O/IND189/2013 (KM264361)

O/NEP/6/2013 (KM921854)

O/IND222/2013 (KM264364)

O/BAN/GA/Ka-213/2014 (KY077606)

O/BAN/GA/Ka-215/2015 (KY077607)

O/UAE/1/2014 (KM921877)

UAE/2/2014 (KM921878)

98 O/NEP/4/2014 (KM921863) O/NEP/5/2014 (KM921864)

- O/NEP/9/2014 (KM921868)

776 O/NEP/15/2013 (KM921857)

52 O/NEP/18/2013 (KM921860)

${ }_{89}$ O/NEP/7/2014 (KM921866)

O/BAN TA Dh-186 2013 (KJ175185)

97 O/LAO/12/2015 (KY399461)

O/LAO/11/2015 (KY399460)

95 O/VIT/9595/2015 (KY399464)

${ }^{95}{ }^{\mathrm{O} / \mathrm{VIT} / 17867 / 2015 \text { (KY399466) }}$

$89-O / V I T / 18280 B / 2015$ (KY399467)

70 O/VIT/16451/2015 (KY399465)

${ }_{67}$ O/VIT/16451DLBPP04/2015 (KY657269)

- O/BHU/1/2013 (KM921828)

8 O/IND50/2013 (KM264358)

O/NEP/16/2012 (KM921851)

9 O/NEP/10/2012 (KM921848)

O/NEP/13/2012 (KM921850)

O/NEP/11/2012 (KM921849)

O/NEP/16/2013 (KM921858)

[ O/NEP/17/2013 (KM921859)

/IND127/2013 (KM264359)

$64 \mathrm{O} / \mathrm{LIB} / 3 / 2013$ (KM921831)

$\mathrm{O} / \mathrm{LIB} / 6 / 2013$ (KM921834)

O/LIB/2/2013 (KM921830)

$56-\mathrm{O} / \mathrm{LB} / 13 / 2013$ (KM921838)

67-O/LIB/17/2013 (KM921840)

93 O/LIB/1/2013 (KM921829)

[ O/LIB/22/2013 (KM921841)

O/LIB/16/2013 (KM921839)

- O/IND52/2013 (KM264360)

71 64 O/SAU/7/2013 (KM921873)

77 O/SAU/8/2013 (KM921874)

O/SAU/6/2013 (KM921872)

96-O/SAU/1/2014 (KM921875)

${ }^{96}$ O/IND179/2013 (KM264357)

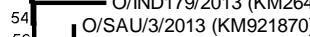

96 O/SAU/1/2013 (KM921869)

94 O/IND160/2011 (KC506499)

O/IND8/2010 (KC506452)

L O/IND104/2010 (KC506467)

8 O/BHU/3/2009 (KM921814) (prototype d)

89 O/BHU/16/2009 (KM921821)

O/BHU/25/2009 (KM921825)

7 O/BHU/26/2009 (KM921826)

O/BHU/23/2009 (KM921824)

- O/IND32/2012 KC506511)

O/BAN/1/2009 (HQ630676)

O/IND220/2010 (KC506481)

O/BHU/2/2009 (KM921813)

O/BHU/5/2009 (KM921816)

O/NEP/5/2010 (KM921843)

98

- O/IND181/2010 (KC506477)

- O/BAN/28/2009 (HQ630689)

- O/BHU/10/2009 (KM921820)

O/BHU/19/2009 (KM921823)

O/NEP/3/2009 (KM921842)

95 O/NEP/4/2012 (O/KM921846)

O/NEP/6/2012 (KM921847)

57 - O/BHU/12/2012 (KM921827)

$97-O / B$ O/NEP/21/2012 (KM921852)

O/IND/OTNNa1211/2011 ( (JX070623)

O/NEP/17/2015 (KY449050)

76 O/NEP/5/2016 (KY449053)

O/NEP/6/2016 (KY449054)

BAN/NL/Lo-245/2015 (KY077611)

O/MOG/BU/2-7/2015 (LC320038)

L O/XJBC/CHA/2017 (KY696708)

BAN/GO/Ka-236(Pig)/2015 (KX712091)

O/XJPS/CHA/2017 (KY696707)

88 O/MYA/2493/2015 (KY399469)

O/MYA/2496/2015 (KY399470)

BAN/SI/Sh-234/2015 (KY077610)

99 O/Ind-2001

64

O/Ind-2001

O/BAN/TG/Ba-268/2015 (KY077621)

O-Ind-2001d

0-Ind-2001

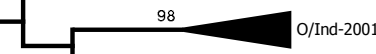

O/JOใ/2/95 (DQ164903)

O/NEP/111/90 (DQ164929)

O/UKG/35/2001 (AJ539141) 
Figrę̧3re 3 


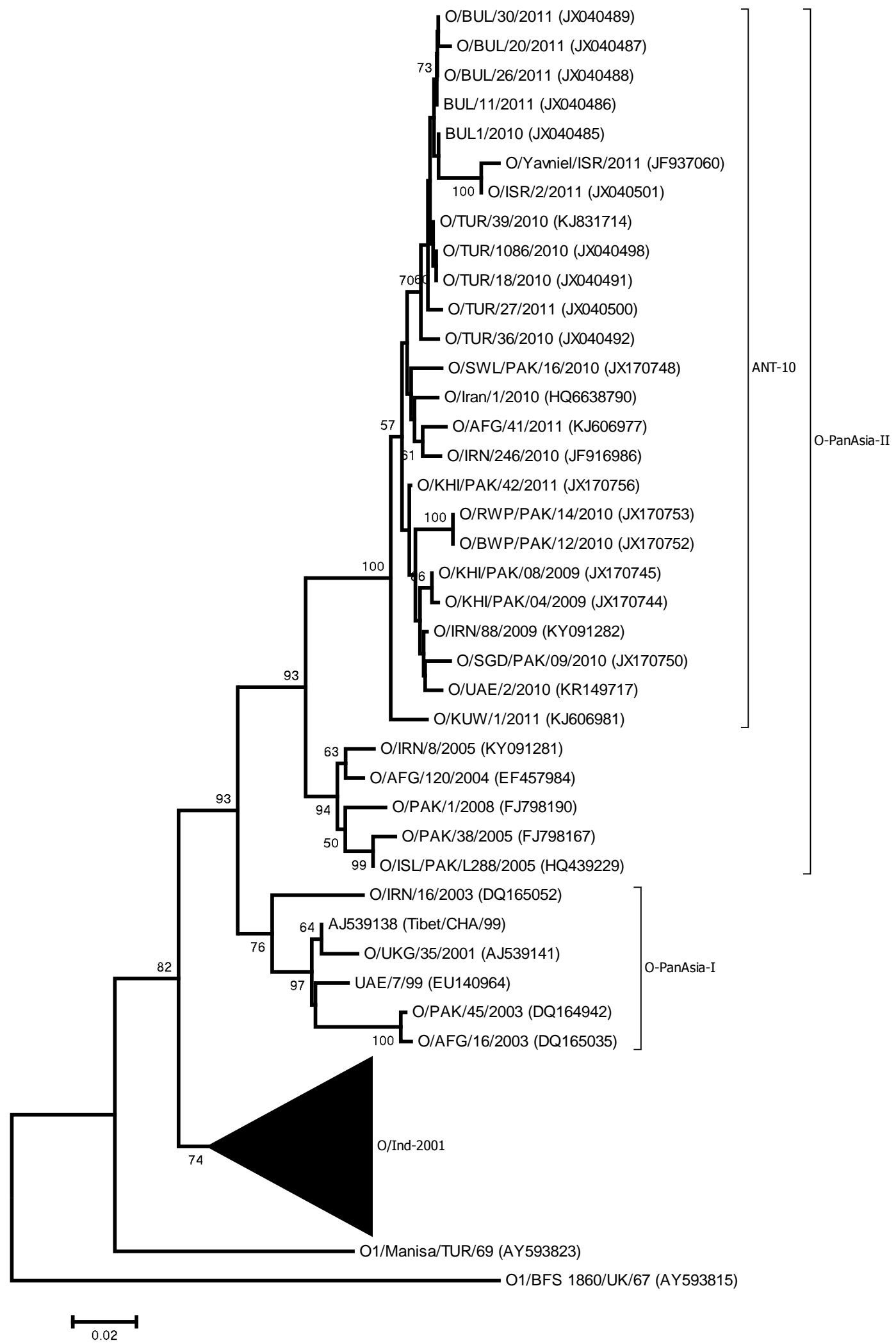




\section{Figures
Figure 5

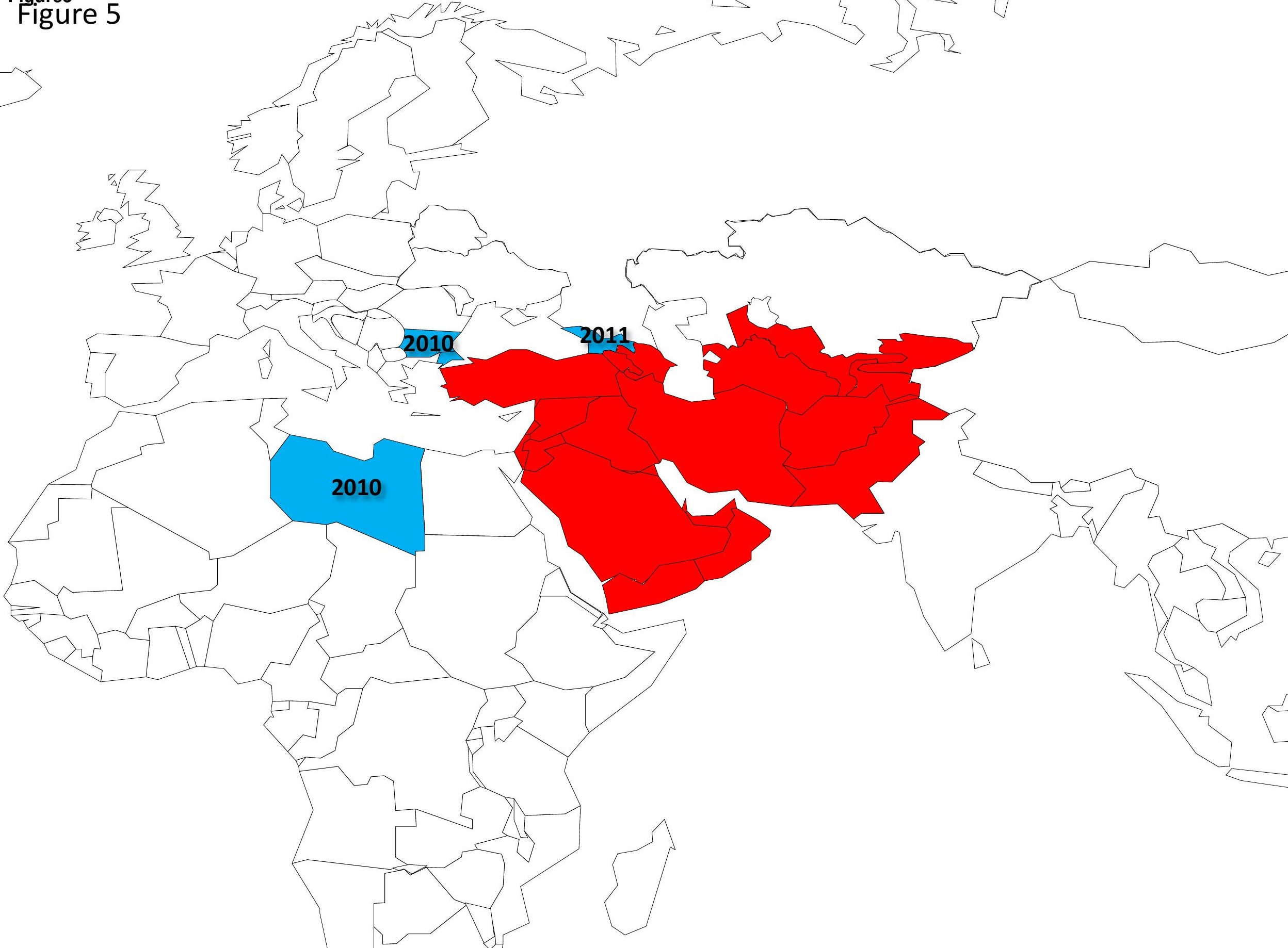


SAR/AFG/L1434/2009_(HQ439273)

A/EGY_1/2012_(KC440882)

A/LIB/14/2009_(KF112913)

A_isolate_4258_(JN099702)

L A/IRQ/24/2009_(KF112909)

A/Egy/Menoufia/2010_(KC888938)

$59-\mathrm{A} / \mathrm{IRN} / 23 / 2009$ (KF112908)

- KAB/AFG/L1163/2008_(HQ439262)

85 BAR/6/2008_(FJ755010)

L BAR/7/2008_(FJ755011)

SIN/PAK/L739/2009_(HQ439249)

88 SIN/PAK/L758/2009_(HQ439250)

SIN/PAK/L695/2009_(HQ439248)

94 SIN/PAK/L693/2009_(HQ439246)

- SIN/PAK/L3213/2009_(HQ439260)

SIN/PAK/L694/2009(HQ439247)

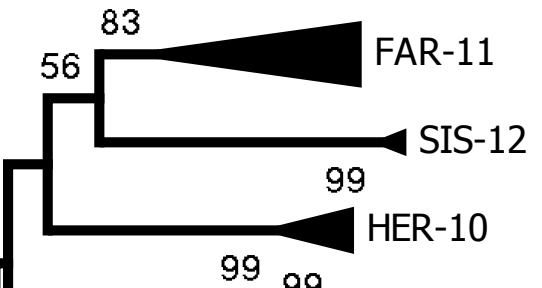

${ }^{99} 99$

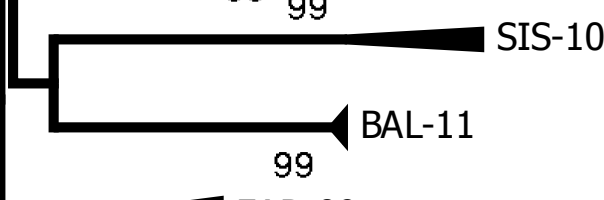

95

4 AFG-07

99
A/IRN/1/2005_(EF208769)

A-Iran05

99

L A/IRN/5/2005_(FJ755025)

A/TUR/8/2005_(FJ755096)

A/AFG/183/2005_(EF457983)

A/AFG/160/2005_(EF457982)

A/SAU/16/2005_(FJ755087)

51 A/SAU/15/2005_(FJ755086)

Pak/3/2006_(FJ755083)

$99 \begin{aligned} & \text { A/PAK/3/2006_(EF117837) } \\ & \text { PAK/1/2006 }\end{aligned}$

TUR/324/2007_(FJ755126)
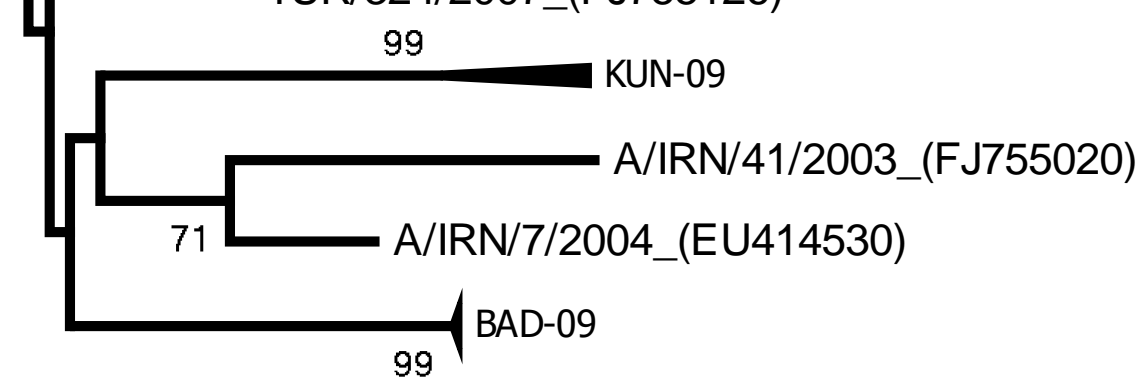

IRN/1/2008_(FJ755066)

$90 \_$IRN/15/2007_(FJ755061)

QAZ-11

70 TUR/186/03/98_(DQ296536)Irn96

LTUR/89/02/98_(DQ296535)Irn96

99 TUR/45/01/98_(DQ296542)Irn96

IRN96

TUR/382/06/99_(DQ296550)_Irn99

TUR/1263/11/00_(DQ296544)_Irn99

TUR/214/06/03_(DQ296548)_Irn99 
ritgurüre 7

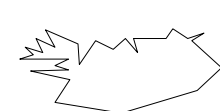

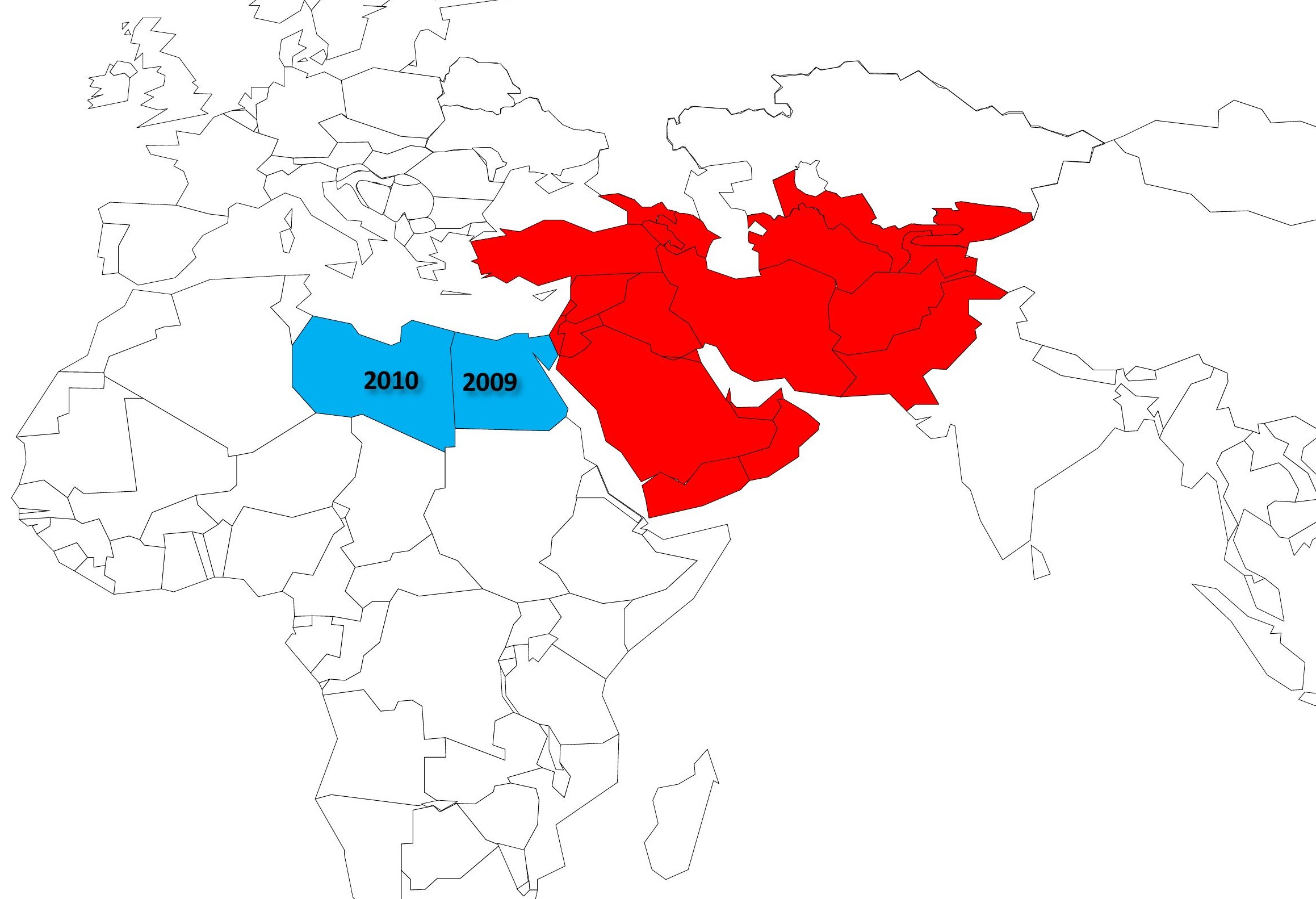




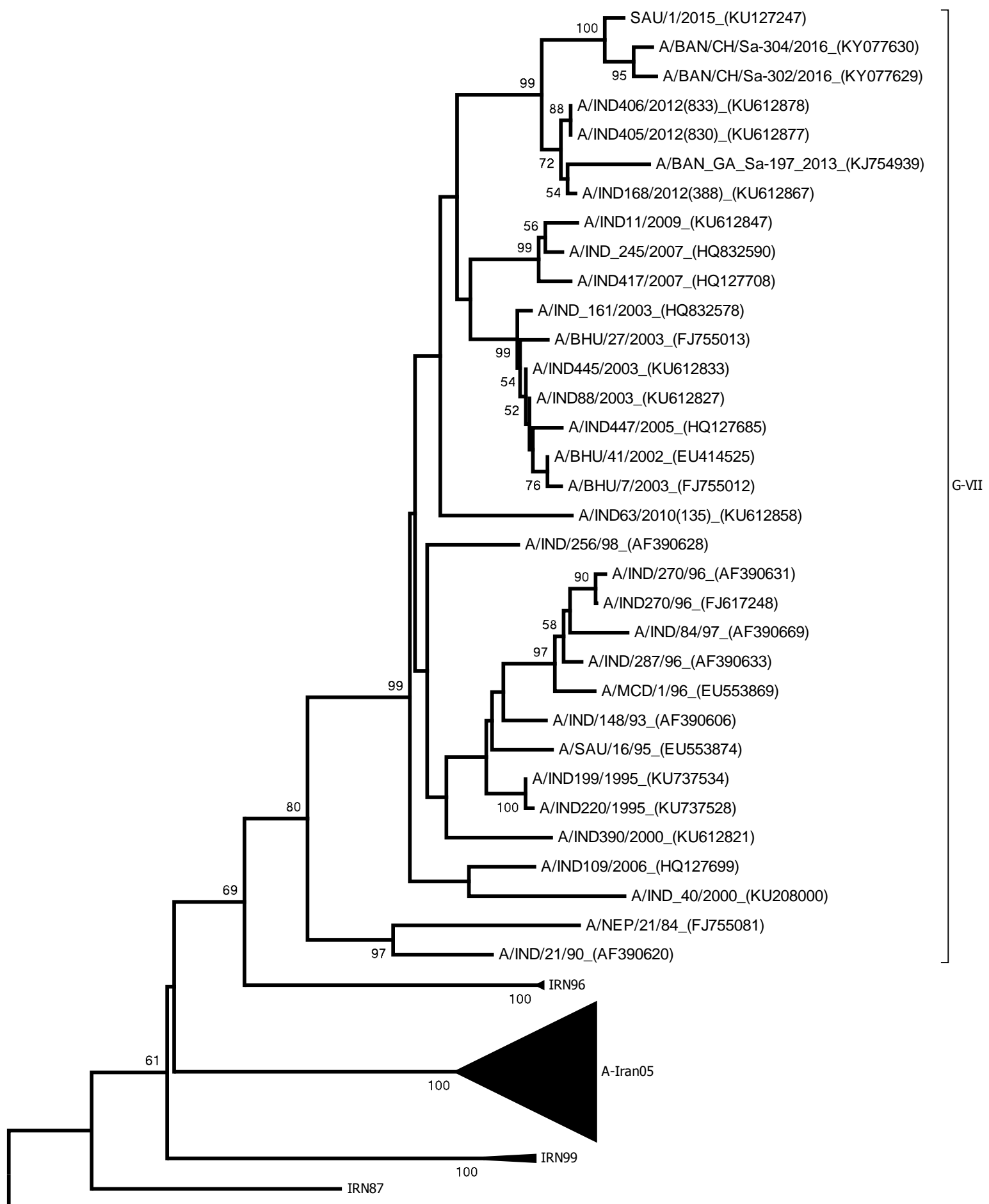

- A22/IRQ/64_(AY593763)

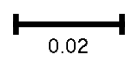




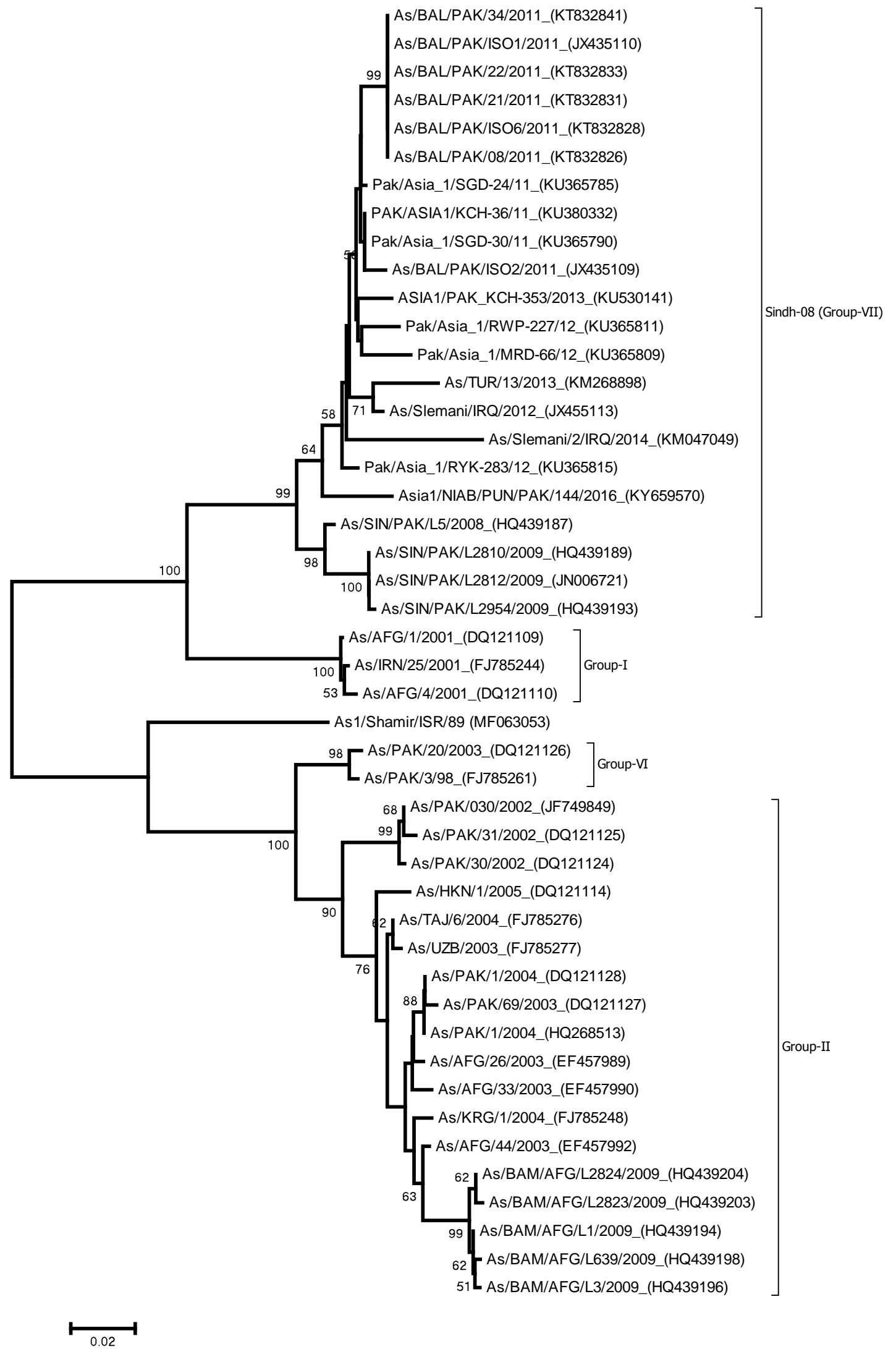

